\title{
A Qualitative Exploration of STEM Career Development of High School Students in Taiwan
}

\author{
Jiaqi Li, Wei-Cheng Joseph Mau, Shr-Jya Chen, Tzu-Chi Lin, and Ting-Yu Lin
}

\begin{abstract}
Although personal inputs and contextual variables in social cognitive career theory (SCCT) are recognized as key factors that affect career interests and choices, research has given minimal attention to the role of these variables in a collectivistic culture context. We present a study examining science, technology, engineering, and mathematics (STEM) career decision-making process of 12 Taiwanese high school students aged 15-17, using a consensual qualitative research method. The data analysis resulted in four domains: personal input, contextual variables, outcome expectations, and self-efficacy identified by SCCT. These results provide a foundation for future research on cross-cultural STEM career development. Implications highlight the importance of counselors in encouraging students of collectivistic culture background to pursue STEM careers.
\end{abstract}

Keywords STEM career development, qualitative methods, Taiwan high school students

Globally, science, technology, engineering, and mathematics (STEM) workforce contributes to the vitality of an economy by promoting innovation and supporting the quality of jobs and exports for many countries. According to the Organization for Economic Cooperation and Development (2012), a number of countries have adjusted their educational policy focus to attract more students (e.g., underrepresented populations, talented young people) in STEM disciplines. Although research has consistently confirmed STEM job growth (Fayer, Lacey, \& Watson, 2017), there still is a paucity of students choosing STEM careers, particularly among women and underrepresented minority groups (Howard et al., 2011; Rottinghaus, Falk, \& Park, 2018; Stipanovic \& Woo, 2017). Concerns about the gap between social demands for more college students entering STEM fields and inadequate preparation of high school students are ubiquitous and drawing special attentions to researchers.

In the past two decades, social cognitive career theory (SCCT; Lent, Brown, \& Hackett, 1994) has become a popular framework to build linkages between existing theoretical approaches to STEM career development. Specifically, SCCT emphasizes that personal input variables interact with contextual variables to affect learning experiences that promote self-efficacy and outcome expectations of career behaviors. Despite the promising findings through SCCT, there is still a need to investigate personal inputs and contextual variables (Sheu \& Bordon, 2017), particularly involving diverse samples and from a qualitative perspective (Lent, Brown, \& Hackett, 2000). Thus, based on the SCCT frame-work (Lent et al., 1994) using the consensual qualitative research method (CQR; Hill, 2010), we attempted to investigate how Taiwanese high school students in an urban setting envision their career development. Specifically, we explored how high school students arrive at STEM career decisions and what factors they consider in their decision-making process in a collectivist culture setting.

\section{High School Students' STEM Career Development}

The high school years are a critical time when students are planning their STEM career development in different domains and making career decisions (Falco, 2017; Fouad \& Santana, 2017; Sadler, Sonnert, Hazari, \& Tai, 2014; Sahin, Ekmekci, \& Waxman, 2018). As far as parents and teachers are concerned, career development becomes more and more significant to high school students who have to make the decision to proceed to higher education or transition to workforce (Falco, 2017; Lent \& Brown, 2013; Shin, Rachmatullah, Roshayanti, Ha, \& Lee, 2018). According to SCCT, these concerns may be understood by personal (e.g., gender) and contextual (e.g., supports, barriers) variables that influence 
career-related interests and choice behavior (Lent et al., 2000; Sheu \& Bordon, 2017). Lent, Brown, and Hackett (2000) stated that contextual variables may assert a direct influence on individual's career decision-making in a collectivist culture. Specifically, previous research has indicated that the SCCT has been tested and confirmed in several studies with recruited samples from East Asian countries (Sheu \& Bordon, 2017). For instance, Shin, Rachmatullah, Roshayanti, Ha, and Lee (2018) in their investigation of 2,171 Indonesian and Korean high students found contextual variables, educational experience, and parental support play a vital role in understanding STEM career development. In another recent study of mixed Asian and Asian American samples, personal interests and contextual variables were found to be predictive of career choice making (Hui \& Lent, 2018). Despite the promising findings, relatively few studies provided the level of insight and depth that can be obtained in qualitative research by examining these variables, especially for personal inputs and contextual variables, in a collectivist culture.

\section{Academic Background of High School Students in Taiwan}

Like U.S. compulsory education laws (i.e., No Child Left Behind Act, 2002), compulsory education in Taiwan is a 12-year system, including (a) 6 years of elementary education (Grades 1-6), (b) 3 years of junior high school education (Grades 7-9), and (c) 3 years of senior secondary education (Grades 10-12). Senior secondary education offers two 3-year academic tracks for students who are interested in pursuing either 4-year college/university or vocational technological schools. Typically, students must take two important exams: (a) senior high school entrance exam and (b) joint university entrance examination (Magaziner, 2016). According to Chou, Liu, Lin, and Liu (2015), the senior high school entrance exam is so competitive that only the top $20 \%$ of exam takers can enter the academic tracks (e.g., excellent high schools) and the rest will go to the vocational schools. The academic competition for senior high schools is more intense because they must prepare for the college entrance exam and decide their future majors before they enter colleges. Moreover, the pressure of high school and college entrance exam results in few STEM programs existing in Taiwan public K-12 schools (Lou, Chen, Shih, Tsai, \& Tsai, 2009). Senior high school students do not have a chance to change their majors and the possibility of admission to the certain majors (i.e., STEM) is decided by the scores they obtain in the college entrance examination only (Tien \& Wang, 2016).

\section{SCCT}

The SCCT (Lent et al., 1994) is a well-substantiated theory for investigating the role of person, environment, and cognitive process in the career development. It postulates how self-efficacy and expected outcomes interact with personal inputs and contextual variables in the process of career development (Lent et al., 1994). In general, SCCT is primarily derived from social cognitive theory (Bandura, 1986) and has long been applied in STEM research to explain career-related behaviors and expectations from middle schoolers to undergraduates (Lent et al., 2000; Lent, Lopez, Lopez, \& Sheu, 2008). According to Lent, Brown, and Hackett (1994), personal inputs, or person factors, mainly focus on gender and race/ethnicity due to their unique attributes as socially constructed source of influence on career interests and choices. Contextual variables refer to a variety of factors that (a) shape the learning experiences that impact personal interests and choices and (b) form a practical opportunity structure within which career plans are developed and implemented (Lent et al., 1994). Self-efficacy refers to a belief that one can successfully execute the behavior required to produce the outcomes (Bandura, 1977), and outcome expectations are considered personal beliefs about the consequences of performing particular behaviors (Lent et al., 1994). Self-efficacy and outcome expectations are influenced by personal inputs, contextual variables, and learning experiences. More specifically, STEM self-efficacy beliefs are influenced by four primary resources of information: (a) mastery experience (or performance accomplishment; previous experience and performance), (b) vicarious experience (learning through observation), (c) social persuasion (or verbal persuasion; others' feedback and support), and (d) 
physiological reaction (emotional arousal; Bandura, 1977; Gist \& Mitchell, 1992). Moreover, self-efficacy has been found to be predictive of academic- and career-related goals (Rottinghaus et al., 2018). Within the SCCT, students' choice to pursue or avoid STEM careers could be understood as the interaction among personal inputs, contextual variables, self-efficacy, and out-come expectations.

\section{Present Study}

Based on the structure of SCCT (Lent et al., 1994), the current study was undertaken to mainly explore personal inputs, contextual variables, self-efficacy, and outcome expectations from a crosscultural lens. More specifically, this study was to confirm and expand the literature of the applicability of the SCCT model to groups of individuals in a collectivist culture (Sheu \& Bordon, 2017). This understanding will augment research that advances theory related to making STEM career choices during high school. The research questions guiding this study are "how do Taiwanese high school students describe their STEM career development?"

\section{Method}

Given the exploratory nature of this investigation, we determined that a qualitative approach would provide us with the most effective way of answering our research questions. In particular, we conducted two focus groups to collect our data and used a CQR (Hill, 2010; Hill et al., 2005) method to analyze the data. Compared with other qualitative approaches, CQR uses open-ended questions, semistructured interview protocols, a research team, and an auditor to evaluate and validate the data (Hill et al., 2005). These distinctive features of CQR allowed us to gain a complete and accurate understanding of our findings.

\section{Participants}

Participants were 12 high school students between the ages of 15 and 17 years $(M=16.2, S D=$ .79). Six participants self-identified as male and six self-identified as female. Ethnically, all participants identified themselves as Han (Note that ethnic groups include Han, Taiwanese aborigines, and foreign residents in Taiwan; aboriginal people are an ethnic minority group, while Han belongs to a majority group.) All participants reported living in urban setting. Socioeconomic status for participants was collected by local school teachers and not revealed to researchers due to the local school confidentiality policy. The inclusion criteria were as follows: (a) 10th-grade students, (b) balanced gender, (c) diverse socioeconomic status, (d) interest in STEM career, and (e) a maximum of 15 participants. The inclusion criteria were gathered from are view of the literature that (a) gender-balanced, socioeconomically diverse students would result in a broad range of outcome expectations (Rubin \& Rubin, 2012) and (b) an ideal sample size for CQR should be between 12 and 15 participants (Hill, 2010).

\section{Procedure}

Upon approval from an institutional review board, participants were selected from the population of 380 tenth-grade students at a university prep high school in Taiwan. Purposeful sampling procedures (Patton, 2002) were used to obtain the sample participants who met the criteria of the study, specifically those who showed interests in STEM career. As ways of recruiting participants, the third author sent messages through local high school teachers as well as paper flyers describing the study to all 10th-grade classes after obtaining the approval from the local high school principle. Potential participants contacted their teachers and provided informed consent. Two senior high school teachers and one guidance counselor helped screen candidates and rule out ones who did not meet the criteria. There was not any reward or compensation for all participants.

Focus group interview. According to Rubin and Rubin (2012), focus group interviews were used to develop themes that are reflective of group-level experiences as well as personal thoughts and feelings. 
In particular, focus group interviews can empower participants from East Asian countries to express their opinions and emotions (Lee \& Lee, 2009). Thus, this study is consisted of two 60-min focus groups with six participants and was held in a private conference room at a local high school the most convenient time and location for students. Each group participant was identified by two senior teachers to reflect a range of academic and socioeconomic backgrounds. The second author facilitated two focus groups with a graduate assistant (note-taking) in 2 times (i.e., during lunch recess) and included team-building activities (e.g., icebreakers) at the outset to increase participants' comfort and willingness to share their experiences. The same focus group interview format was followed in the next group and both groups were conducted in Chinese. The second author led the discussion while the graduate assistant took notes and audio recorded the sessions. In the beginning of the focus group interviews, the second author asked participants to share both positive and negative experiences with STEM career interests and planning in a crosstalk format. In addition, the second author instructed the participants not to focus on consensus but express their personal perspectives on the subject. The role of the second author included (a) giving topics and distributing speech turns and (b) eliciting storytelling or argumentation.

Semistructured interview. The research team used in-depth, semistructured interview questions as a guide. These questions were developed based on the empirical literature (Lent et al., 1994, 2000) and research question of increasing understanding about how Taiwan high school students envision their STEM career development. The questions were designed in a way that participant responses would confirm or expand upon existing literature regarding the key factors influencing students' career decisionmaking in a collectivist culture. Prior to conducting the first interview, the research team pilot tested the interview protocol and modified confusing questions as well as the interview process. The interviews were recorded by researcher (second author) and audiotaped with participant consent and transcribed for later coding. At the end of the interviews, participants were given opportunity to review written notes for clarifications or omissions, and they were assured that their names or identifying information was not included in the data report.

The interview questions included a set of 10 open-ended questions that addressed the research questions. For instance, Questions 1 and 2 asked about career interests and choices (e.g., "what is your favorite job?"); Question 3 focused on personal experiences about math or science courses (e.g., "can you describe your experiences and feelings of math and science courses"); Questions 4 and 5 asked about future career planning (e.g., "what is your career plan after going to college?"); Questions 6 and 7 focused on gender and ethnicity (e.g., "do you think what influences your gender will have on your career decisionmaking"); Questions 8 and 9 asked about STEM career supports and barriers (e.g., "what supports will you expect to get to help you enter an STEM career?"); and Question 10 focused on the critical factors in an STEM career decision-making process (e.g., "which factors do you find to be most important in your STEM career decision-making process?").

\section{Data Analysis}

Data were analyzed following CQR guidelines (Hill, 2010): (a) developing domains or general themes (e.g., develop a domain list, verify and update the domain list, develop consensus version of interview data), (b) constructing categories (e.g., edit interview data in each domain, audit the consensus version), and (c) cross-analyzing the data (e.g., combine all participants into one data set, identify common themes, send to auditor for final audit). As such, the research team members began with creating a list of domains after independently reading each of the focus group transcripts. The research team members then met and discussed their lists of domains and came to consensus about analytical findings through open and critical discussions. Subsequently, researchers created categories in each domain by using the final list of domains as a guide. When disagreements during any part of the analysis came up, researchers went back to the raw data until consensus was reached. Lastly, the team met and analyzed all categories and core ideas to ensure that the data were accurately presented. A final list of categories was developed, 
and frequency labels were applied according to CQR guidelines (Hill, 2010). That is, a category is labeled general if a theme is found in all, or all but one cases; typical if a theme is from more than half of cases, and variant if a theme is from at least two cases up to half of cases. An auditor reviewed all identified categories and provided detailed feedback for the research team members.

\section{Research Team}

As suggested by Hill (2010), our research team consisted of four faculty members and two graduate research assistants in order to ensure more trustworthy results. All research team members shared similar research interests and perceptions on this topic. One of the research members served as an external auditor in this study. The rest of the members participated in developing interview questions and protocol and collecting and analyzing data. Prior to beginning any data collection, research team members were encouraged to openly discuss their experiences and concerns on the project.

Table I. Summary of Domains, Categories, Frequency, Environmental, and Individual Factor.

\begin{tabular}{llc}
\hline Domains & Categories & Frequency \\
\hline Personal inputs & Gender & $\mathrm{T}$ \\
& Ethnicity & $\mathrm{V}$ \\
Contextual variables & Teacher support & $\mathrm{G}$ \\
& Family influences & $\mathrm{G}$ \\
& Childhood dream jobs & $\mathrm{G}$ \\
STEM career outcome expectations & Academic performance & $\mathrm{T}$ \\
& Job market trends & $\mathrm{V}$ \\
& High-paying jobs & $\mathrm{G}$ \\
STEM career self-efficacy & Positive work environment & $\mathrm{T}$ \\
& Math/science self-efficacy & $\mathrm{V}$ \\
& STEM education experiences & $\mathrm{T}$ \\
& Social influences & $\mathrm{G}$ \\
\hline
\end{tabular}

Note. $\mathbf{G}=$ general $(\mathrm{I} \mathrm{I}-12$ responses); $\mathrm{T}=$ typical $(7-10$ responses); $\mathrm{V}=$ variant $(2-6$ responses); $\mathrm{STEM}=$ science, technology, engineering, and mathematics.

\section{Trustworthiness}

According to Hill (2010) and Hill, Thompson, and Williams (1997), there are several criteria required to establish the trustworthiness of a CQR study. First, we pilot tested our interview questions and protocol until a consensus was reached. These pilot tests allowed researchers to examine whether the whole interview process functioned properly and logically. Second, we used an auditor to provide feedback on coding and data analysis. The research team reviewed the auditor's feedback and came to consensus about revisions. Last, all research team members discussed their expectations and biases that might have affected the coherence of the results. This allowed researchers to identify their own perceptions and interpretations of the data.

\section{Results}

As shown in Table 1, based on the questions in our semistructured interview, our analysis resulted in four domains: (a) personal inputs, (b) contextual variables, (c) outcome expectations, and (d) career self-efficacy. The first domain, personal inputs, included two categories (i.e., gender, ethnicity). The second domain, contextual variables, contains four categories (i.e., teacher support, family influences, childhood dream jobs, academic performance). The third domain, STEM career outcome expectations, consisted of three categories (i.e., job market trends, high-paying jobs, positive work environment). Finally, the fourth domain, STEM career self-efficacy, yielded three categories (i.e., math/science selfefficacy, social influences, STEM education experiences). In addition, five categories labeled as general (i.e., teacher support, family influences, childhood dream jobs, high-paying jobs, social influences), four 
categories labeled as typical (i.e., gender, academic performance, positive work environment, STEM education experiences), and three category labeled as variant (i.e., ethnicity, job market trends, selfconfidence in math/science) emerged from the cross-analysis of the interviews.

\section{Personal Inputs}

In the first domain, we identified one typical and one variant category reflecting the definition of personal inputs in the SCCT (Lent et al., 1994). The first category, gender, was a typical theme found in eight interviews that described the impact of gender on STEM career decision-making. For example, Student 1 expressed her concerns in deciding an STEM career because Student 1 perceived "some STEM jobs" as "boys' majors that girls should not step in." For example, Student 1 stated (note that all quotes have been translated from Chinese to English):

I am not interested in those majors such as civil engineer and computer science because they are majors for boys [other group members voicing agreement] ... I will surely get bullied if I choose those majors (e.g., architecture engineering) because I do not have muscle [group laughter].

Another category, ethnicity, was identified as variant given that it only consisted of five responses in the interview. In this category, students discussed the influences of their ethnicity on career choice and interests. Student 2 noted that "I do not think that aborigines will be discriminated in applying for a university major or finding a job." Student 3 identified another example: "aborigines thought we [Han] discriminate them ...but I think that we have equal opportunities in finding a job." Interestingly, although our participants belong to majority group, they expressed their desire for the equal admission policy as the minority group.

\section{Contextual Variables}

In the second domain, we identified three general and one typical categories indicating participants' thoughts and experiences about contextual and background factors that are important to academic and career behaviors. As indicated by Lent et al. (1994), examining contextual factors will help researchers have a better understanding of an individual's "phenomenological role as the interpreter of contextual inputs" (p. 106). Three general categories consisted of teacher support, family influences, and child-hood dream jobs because they were found in most of the interviews (11 and 12 responses). Examples of general categories on career choice included "I dream of becoming an engineer because of a cartoon I watched when I was young" (childhood dream jobs), "I hope my teachers can help me make a career choice" (teacher support).

Interestingly, more than half of the participants reflected similar family influences on their career choice. For example, Student 4 stated:

My parents do not want me to go for those majors [e.g., K12 education] that I will be unable to make too much money after graduation [other group members voicing agreement]. If I disagree with them, they will keep bothering me every day [group laughter]. Thus, I must listen to their suggestions when I am ready to choose college majors. I do not want to make them unhappy [other group members voicing agreement]. However, I know that they want me to have a comfortable job. If I could find one that fulfills my dream and makes more money, they would say yes [other group members voicing agreement]. 
The typical category, labeled as academic performance, was well represented in Student 5's interview:

I do not know whether or not I like it (i.e., computer science)...this might depend on my grades on math and science. I do not think that I have a brain for math ... I am thinking of other majors (e.g., nurse) when I go to college [other group members voicing agreement].

Another student [Student 6] described the theme academic performance as his advantage because "I am good at math ... I want to become a computer programmer." However, some students reported that they will choose majors in computer science or electrical engineering, even if their academic performance is not good enough.

\section{Outcome Expectations}

The third domain was composed of three categories that described participants' understanding of what they will expect after successfully achieving their STEM career development. Specifically, these categories reflected participants' expectations of STEM career outcome. The first theme, high-paying jobs, was a general theme found in all interviews that described each participant's direction in pursuit of their career goals. One of the participants [Student 7] described what he believes he needs to have for his future job.

I do not care too much on what types of jobs I will choose; however, my parents suggested that I should find a job that is high-paying [group laughter, other group members voicing agreement], close to where my parents live [group laughter, other group members voicing agreement], and has a positive working environment (i.e., do not want to have too much work stress).

Interestingly, 10 participants also reported the importance of positive work environment as a typical theme. Students defined positive work environment as "low stress, high job security, and ideal job location." Student 8 commented,

I do not like the current educational system [Taiwan] because students have too much stress... we are competing for good grades over and over again [other group members voicing agreement]... I am almost burned out and do not want to continue to burn out when I go to work [group laughter].

Another student, Student 4, discussed ideal job locations, stating, "I want to find a stable job here in this city and do not stay far away (e.g., relocate to another city in Taiwan) from my parents [other group members voicing agreement]."

Only 2 of the 12 participants made comments related to job market trends in the interviews. For example, Student 9 stated, "the whole society pays more attention to math/science ...students who have good grades in math/science can find a decent job." Common perception for these two students (Student 8 and Student 9) is that Taiwan's economy is unpredictable, but graduates holding an STEM qualification could have an advantage place in the job market.

\section{Career Self-Efficacy}

The domain STEM career self-efficacy was developed based on Bandura's $(1977,1994)$ selfefficacy theory and evidenced in the interviews. Although not all participants used the same language to describe their self-efficacy beliefs and experiences (e.g., math/science self-efficacy, STEM education 
experience, social influence), all of them are able to use their own words to explain how self-efficacy directly impacts their career interests and goals.

The first theme, math/science self-efficacy, was a variant category found in 5 of the 12 interviews. In this theme, researchers noticed mastery experiences of students on their performance in math and science. For instance, Student 10 explained:

I did not like math/science when I was very young. But when I came to high school and found that I can solve some difficult math questions, I started to feel a strong sense of achievement and self-confidence.

STEM education experience was another typical category that focused on students' past successful experiences that boosted their self-efficacy on STEM career interests. These experiences included after school math tutoring program, science fair experiments, math and science tournament, and job shadowing events. For example, Student 9 noted that

I have a sense of achievement in math and science after I obtained good scores in MC (i.e., a math and science tournament) ... also I attended an after-school math tutoring program and it helped me a lot in math ... I did not feel that the math is too difficult for me.

The last theme, social influence, was a typical category found in 10 of the 12 interviews that described verbal persuasions from teachers, parents, and social media to motivate students to pursue STEM-related careers. For example, Student 7 expressed an interest in exploring STEM careers because his parents verbally encouraged him to "display his talent in scientific areas of study." Another student [Student 11] was intrigued by support of her math teacher, "My math teacher helps me establish selfconfidence in math. Although I know many future majors and jobs related to math, I think that I will be able to handle them." In addition, many students believed that they have ability to complete STEM-related majors and find a job in STEM disciplines because they received some positive information related to STEM career development through social media.

\section{Discussion}

In this study, we used SCCT (Lent et al., 1994) as a framework to better examine how a group of Taiwanese high school students perceive their STEM career development. Our analysis of inter-views of 12 participants reflected four domains associated with STEM career development: personal inputs, contextual variables, outcome expectations, and career self-efficacy. Within these domains, 12 categories and three types of frequency were identified by using CQR (Hill, 2010). These results were supported by previous research (Chou, Liu, Lin, \& Liu, 2015; Mau, 2003; Mau \& Bikos, 2000; Robnett \& Leaper, 2013; Tien, 1996) and expanded our knowledge in understanding SCCT (Lent et al., 1994) in a cross-cultural context. In the following, we discuss the findings in relation to the SCCT domains.

\section{Personal Input}

Given the structure of SCCT (Lent et al., 1994), our findings reflected that gender and ethnicity are related to career development (i.e., supports and barriers). Interestingly, 67\% of participants (e.g., four female students) reported that women are discouraged in part by stereotypes associating STEM fields with men and masculine traits, whereas $42 \%$ emphasized the positive impact of ethnicity (i.e., aboriginal students belong to ethnic minorities in high schools in Taiwan) on admissions to college/university. For example, there are some supportive and beneficial programs (e.g., special enrollment policies, scholarship) for aboriginal students in Taiwan (Hou \& Huang, 2012). These findings support previous 
research investigating roles of gender and ethnicity in STEM career choice and participation ( $O^{\prime}$ Brien, Blodorn, Adams, Garcia, \& Hammer, 2015; Tien, 1999). In the investigation of 584 high school students in Taiwan, Tien, Wang, and Liu (2009) found that female students perceived more barriers than male students regarding gender discrimination in the process of career decision-making. Similarly, Bernhard, Silke, and Manuela (2017) reported that gender stereotypes were negatively related to students' STEM career planning in their survey of 296 German female students. Moreover, our results are consistent with May and Chubin's (2003) findings that the success of minority students in STEM is related to admission policies and financial assistance. Although participants in May and Chubin's (2003) study consist of African American (i.e., 304 students), Hispanics (425), and American Indians (53), our findings affirm that these factors (e.g., admission policy, financial support) that contribute to the success of underrepresented minority students entering STEM majors in the United States have the same positive effect on minority students in Taiwan.

\section{Context Variables}

The definition and classification for context variables is broad and includes overlapping elements that potentially shape career path (Lent et al., 1994, 2000). Lent et al. (2000) stated that contextual variables contain actual and perceived environmental supports and barriers that are related to career choice goals and actions. Thus, our findings are consistent with the SCCT (Lent et al., 1994) in which contextual variables relate to goals and choices from a perspective of supports or barriers. For example, all participants reported that teacher support has a positive impact on their career development. All participants indicated that family influences either support or are barriers to their preferred career goals. This finding is consistent with the earlier studies (Tien, 1996; Tien, Wang, \& Liu, 2009), which indicated that familial influences (e.g., expectations, support) play a vital role in individual's career development in Asian students. Likewise, after examining the literature, we found that the teacher support we observed in this study most closely aligns with Metheny, McWhirter, and O'Neil's (2008) results. Metheny et al. (2008) stated that higher levels of perceived teacher support were related to higher levels of career development in their investigation of 325 seniors at urban public high schools. In our interview, perceptions of teacher support (e.g., caring and having high expectations for the students) are very important for making career-related decisions and holding outcome expectations for STEM career-related choices.

In addition, 11 (of the 12) participants believed that their future career interests are motivated by their childhood dream jobs. This finding echoed a sizable amount of literature and theories that focus on childhood career development (Hartung, Porfeli, \& Vondracek, 2005; Schultheiss, 2008). Specifically, our study supports Hartung, Porfeli, and Vondracek's (2005) research findings that family and media serve as the primary context of career development during childhood and impact children's understanding of their career behavior and development. Interestingly, the sources of media in our study appear to be mainly consist of TV advertisements, street advertisements, blogs, and Facebook and have become more diversified than the past (e.g., printed and video materials; Hartung et al., 2005). Therefore, future research can focus on how social media theoretically and practically impacts children's career awareness, exploration, and interests in the current social-cultural context.

Lastly, 10 participants emphasized the influence of their academic performance on their STEM career expectations. This finding is in line with educational values and beliefs among Asian American and East Asian students (Chen \& Ho, 2012; Mau, 1997). Influenced by the Confucian belief, Asian students contribute their career success to academic performance (Chao, 1996; Chen \& Ho, 2012; Phillipson \& Phillipson, 2007). Both annual high school entrance exam and joint university entrance exam in Taiwan reflect the belief (Magaziner, 2016). 


\section{Outcome Expectations}

Our findings of outcome expectations provide supports for the social cognitive theory suggesting that anticipation of physical outcome (e.g., financial gain or loss) affects career interests and goals (Bandura, 1986; Lent et al., 1994; Shoffner, Newsome, Barrio Minton, \& Wachter Morris, 2015). Specifically, most participants reported that their STEM career outcome expectations begin with the assumption that STEM jobs offer high income in the near term. The importance of physical outcome expectation to young students' career choice is consistent with prior qualitative findings (Schoffner et al., 2014). These results also have indicated that working in a positive workplace (e.g., relaxed atmosphere, flexibility) and meeting future job market trends (e.g., job security) are two imagined consequences of STEM career path. We found that participants' expectations of high-paying careers and positive working environments are mainly influenced by their family support. It is possible that Asian students tend to conceptualize their outcome expectations as positive expected results based on their academic performance (e.g., math/science) and family support. Along with earlier findings, these results suggest that career outcome expectations continue to reflect strong family support on students' career decision-making in a collectivist culture (Hui \& Lent, 2018; Mau, 2003; Tien, 1996). It is possible that family support helps shape outcome expectations by assisting students to interpret career interests and choice. For example, Byars-Winston and Fouad (2008) found that parental involvement directly and indirectly predicted career goals through its strong relationship with outcome expectations.

\section{Career Self-Efficacy}

Compared with outcome expectations, self-efficacy is portrayed as a more influential determinant of career behavior and interests in our study. We found that the students in our sample, who are interested in pursuing STEM careers, reflect three primary aspects of self-efficacy beliefs (Bandura, 1977; Gist \& Mitchell, 1992): (a) mastery experience (e.g., math/science self-efficacy), (b) vicarious experience (e.g., positive STEM education experiences in the past), and (c) social persuasion (e.g., social influences). Bandura $(1977,1986,1994)$ has repeatedly argued that mastery experience constitutes the most influential source of self-efficacy. Interestingly, we found that social persuasion also appears to play an important role in STEM career self-efficacy. Further research may clarify if this is a unique phenomenon of a collectivist culture. Although students discussed being "poor" and "lack of confidence" in math/science, they still show positive attitudes toward entering STEM careers. This may be a small shift in perception in the recent years, although this is not clear. Given this finding, social persuasion (e.g., media, schools, families) may be especially important for students who are interested in STEM careers.

\section{Limitations}

There are several limitations to this study. First, CQR captures the depth of individual perspectives of STEM career development in a focused group of high school students, and thus, these results cannot be generalized to all Taiwanese students. In addition, this research design does not lead to definite conclusions about cause and effect among variables and themes. Second, we did not include a diverse sample of students that are from underrepresented groups (e.g., aboriginal students) in Taiwan. This lack of diversity could have contributed to the STEM career decision-making processes being less varied in nature and therefore influencing our interpretation of personal inputs and context variables in these groups. Third, self-report bias may exist in our findings. Participants may have reported what they thought were best paths to their career development because they knew that they were being inter-viewed and recorded. In addition, group members might feel peer pressure to give similar answers to the facilitator's questions in a focus group. It requires an experienced facilitator with group counseling skills to moderate this effect. Finally, each group interview was $60 \mathrm{~min}$ in length, and on the aver-age, each student has 10 min to answer the questions. This brevity may have limited our opportunity to capture the depth of student experiences and perceptions. 


\section{Implications and Future Research}

The current study contributes to the literature in two main ways: First, CQR provides depth in the understanding of the inner experiences of individuals (Hill et al., 2005). Personal inputs and contextual variables are two areas with additional research in a cross-cultural context (Sheu \& Bordon, 2017), and through the findings of this study, we can gain a deeper understanding into the process by which high school students make STEM career decisions in a collectivistic cultural setting. However, the study results cannot be generalized to all high school students in Taiwan, nor they can be generalized to Asian American students. Thus, future researchers could avoid this limitation by using a quantitative or longitudinal study design to capture a broader sample for more generalizable results.

Second, it is important for counselors and researchers to be aware of media that may be driving student's choices because students received more career guidance information from TV and Internet than their parents and teachers. Moreover, students seem to be changing their attitudes toward traditional career value that emphasizes "honoring parents" in the current context. To this point, when students express their concerns about career interests and goals, counselors can help students focus on positive outcome expectations and increase their self-efficacy by holding some activities such as college fairs, college visit, career assessment, and STEM role models and mentors (Lapan \& Kosciulek, 2001). Future researchers may examine the effect of media on career interests and goals among high school students. Researchers could also examine the relationship between perceived family supports and barriers and media in affecting individual's career decision-making in a cross-cultural context.

\section{Conclusion}

We believe that this study makes a unique contribution to SCCT research. We add to the growing body of research on STEM career development among high school students in a collectivistic cultural setting. This finding affirms the complexity of STEM career decision-making and the ways in which personal inputs, contextual variables, outcome expectations, and self-efficacy interact during this process. Although high students' career choices are impacted by many factors, school counselors can improve STEM career development by developing positive outcome expectations and increasing self-efficacy for all students.

\section{References}

Bandura, A. (1977). Self-efficacy: Toward a unifying theory of behavioral change. Psychological Review, 84, 191-215. doi:10.1037/0033-295x.84.2.191

Bandura, A. (1986). Social foundations of thought and action: A social cognitive theory. Englewood Cliffs, NJ: Prentice Hall.

Bandura, A. (1994). Self-efficacy. In V. S. Ramachaudran (Ed.), Encyclopedia of human behavior (Vol. 4, pp. 71-81). New York: Academic Press (Reprinted in H. Friedman [Ed.], Encyclopedia of mental health. San Diego: Academic Press, 1998).

Bernhard, E., Silke, L., \& Manuela, P. (2017). The impact of gender stereotypes on the self-concept of female students in STEM subjects with an under-representation of females. Frontiers in Psychology, 8, 1-10. doi:10.3389/fpsyg.2017.00703

Byars-Winston, A. M., \& Fouad, N. A. (2008). Math and science social cognitive variables in college students: Contributions of contextual factors in predicting goals. Journal of Career Assessment, 16,425-440. doi:10.1177/1069072708318901

Chao, R. (1996). Chinese and European American mothers' beliefs about the role of parenting in children's school success. Journal of Cross-cultural Psychology, 27,403423.doi:10.1177/0022022196274002 
Chen, W., \& Ho, H. (2012). The relation between perceived parental involvement and academic achievement: The roles of Taiwanese students' academic beliefs and filial piety. International Journal of Psychology, 47, 315-324. doi:10.1080/00207594.2011.630004

Chou, S., Liu, E., Lin, M., \& Liu, J. (2015). Better peers, better scores? A study of twin junior high school graduates in Taiwan. Applied Economics, 47,3462-3481.doi:10.1080/00036846.2015.1016209

Falco, L. D. (2017). The school counselor and STEM career development. Journal of Career Development, 44, 359-374. doi:10.1177/0894845316656445

Fayer, S., Lacey, A., \& Watson, A. (2017). STEM occupations: Past, present, and future. Retrieved fromhttps://www.bls.gov/spotlight/2017/

Fouad, N. A., \& Santana, M. C. (2017). SCCT and underrepresented populations in STEM fields: Moving the needle. Journal of Career Assessment, 25,24-39.doi:10.1177/1069072716658324

Gist, M. E., \& Mitchell, T. R. (1992). Self-efficacy: A theoretical analysis of its determinants and malleability. Academy of Management Review, 17,183-211. doi:10.2307/258770

Hartung, P. J., Porfeli, E. J., \& Vondracek, F. W. (2005). Child vocational development: A review and reconsideration. Journal of Vocational Behavior, 66,385-419. doi:10.1016/j.jvb.2004.05.006

Hill, C. E. (2010). Consensual qualitative research: A practical resource for investigating social science phenomena. Washington, DC: American Psychological Association.

Hill, C. E., Knox, S., Thompson, B. J., Williams, E. N., Hess, S. A., \& Ladany, N. (2005). Consensual qualitative research: An update. Journal of Counseling Psychology, 52,196-205.doi:10.1037/00220167.52.2.196

Hill, C. E., Thompson, B. J., \& Williams, E. N. (1997). A guide to conducting consensual qualitative research. The Counseling Psychologist, 25,517-572. doi:10.1177/0011000097254001

Hou, H., \& Huang, C. (2012). An analysis of Taiwanese aboriginal students' educational aspirations. Higher Education Studies, 2,79-99. doi:10.5539/hes.v2n2p79

Howard, K. A. S., Carlstrom, A. H., Katz, A. D., Chew, A. Y., Ray, C., Laine, L., \& Caulum, D. (2011). Career aspirations of youth: Untangling race/ethnicity, SES, and gender. Journal of Vocational Behavior, 79,98-109. doi:10.1016/j.jvb.2010.12.002

Hui, K., \& Lent, R. W. (2018). The roles of family, culture, and social cognitive variables in the career interests and goals of Asian American college students. Journal of Counseling Psychology, 65,98109.doi:10.1037/cou0000235

Lapan, R. T., \& Kosciulek, J. F. (2001). Toward a community career system program evaluation framework. Journal of Counseling and Development, 79,3-15.doi:10.1002/8j.1556-6676.2001.tb01938.x

Lee, J.-J., \& Lee, K.-P. (2009). Facilitating dynamics of focus group interview in East Asia: Evidence and tools by cross-cultural study. International Journal of Design, 3, 17-28.

Lent, R. W., \& Brown, S. D. (2013). Understanding and facilitating career development in the 21st century. In S. D. Brown \& R. W. Lent (Eds.), Career development and counseling: Putting theory and research to work (2nd ed., pp. 1-28). Hoboken, NJ: Wiley.

Lent, R. W., Brown, S. D., \& Hackett, G. (1994). Toward a unifying social cognitive theory of career and academic interest, choice, and performance. Journal of Vocational Behavior, 45,79122.doi:10.1006/jvbe.1994.1027

Lent, R. W., Brown, S. D., \& Hackett, G. (2000). Contextual supports and barriers to career choice: A social cognitive analysis. Journal of Counseling Psychology, 47,36-49.doi:10.1037//0022-167.47.1.36

Lent, R. W., Lopez, J. A. M., Lopez, F. G., \& Sheu, H. B. (2008). Social cognitive career theory and the prediction of interests and choice goals in the computing disciplines. Journal of Vocational Behavior, 73, 52-62. doi:10.1016/j.jvb.2008.01.002

Lou, S. J., Chen, P. H., Shih, R. C., Tsai, H. L., \& Tsai, H. Y. (2009). A study of STEM integrated teaching method applied in the nature and science technology field of junior high school (in Chinese). NPUST Humanities and Social Sciences Research, 3, 42-66. 
Magaziner, J. (2016, June 7). Education in Taiwan. World Education News + Reviews. Retrieved fromhttps://wenr.wes.org/2016/06/education-in-taiwan

Mau, W. C. (1997). Parental influences on the high school students' academic achievement: A comparison of Asian immigrant, Asian Americans, and White Americans. Psychology in the Schools, 34,267277. doi:10.1002/(SICI)1520-6807(199707)34:3<267::AID-PITS9>3.0.CO;2-L

Mau, W. C. (2003). Factors influencing persistence in science and engineering career aspirations Career Development Quarterly, 51,234-243.doi:10.1002/j.2161-0045.2003.tb00604.x

Mau, W. C., \& Bikos, L. H. (2000). Educational and vocational aspirations of minority and female students: A longitudinal study. Journal of Counseling \& Development, 78,186-194. doi:10.1002/j.15566676. 2000.tb02577.x

May, G. S., \& Chubin, D. E. (2003). A retrospective on undergraduate engineering success for underrepresented minority students. Journal of Engineering Education, 92, 27-39. doi:10.1002/j.2168-9830.2003. tb00735.x

Metheny, J., McWhirter, E. H., \& O'Neil, M. E. (2008). Measuring perceived teacher support and its influence on adolescent career development. Journal of Career Assessment, 16,218237.doi:10.1177/1069072707313198 No Child Left Behind Act of 2001, 20 U.S.C. § 6301 et seq. (2002).

O’Brien, L. T., Blodorn, A., Adams, G., Garcia, D. M., \& Hammer, E. (2015). Ethnic variation in gender-STEM stereotypes and STEM participation: An intersectional approach. Cultural Diversity and Ethnic Minority Psychology, 21,169-180. doi:10.1037/a0037944

Organization for Economic Cooperation and Development. (2012). Strengthening education for innovation. Retrieved from https://www.oecd.org/media/oecdorg/satellitesites/stieoutlook/files/policyprofile/STI\%200utlook\%2012_\%20PP\%20HR_Education.pdf

Patton, M. Q. (2002). Qualitative evaluation and research methods (3rd ed.). Newbury Park, CA: Sage.

Phillipson, S., \& Phillipson, S. N. (2007). Academic expectations, beliefs of ability, and involvement by parents as predictors of child achievement: A cross-cultural comparison. Educational Psychology, 27,329-348. doi:10.1080/01443410601104130

Robnett, R. D., \& Leaper, C. (2013). Friendship groups, personal motivation, and gender in relation to high school students' STEM career interest. Journal of Research on Adolescence, 23,652-664. doi:10.111/jora.12013

Rottinghaus, P. J., Falk, N. A., \& Park, C. J. (2018). Career assessment and counseling for STEM: A critical review. Career Development Quarterly, 66,2-34.doi:10.1002/cdq.12119

Rubin, H. J., \& Rubin, I. S. (2012). Qualitative interviewing: The art of hearing data (3rd ed.). Thousand Oaks, CA: Sage.

Sadler, P. M., Sonnert, G., Hazari, Z., \& Tai, R. (2014). The role of advanced high school coursework in increasing STEM career interest. Science Educator, 23, 1-13.

Sahin, A., Ekmekci, A., \& Waxman, H. C. (2018). Collective effects of individual, behavioral, and contextual factors on high school students' future STEM career plans. International Journal of Science and Mathematics Education, 16, 69-89. doi:10.1007/s10763-017-9847-x

Schultheiss, D. E. (2008). Current status and future agenda for the theory, research, and practice of childhood career development. Career Development Quarterly, 57,7-24.doi:10.1002/j.21610045.2008.tb00162.x

Sheu, H., \& Bordon, J. J. (2017). SCCT research in the international context: Empirical evidence, future directions, and practical implications. Journal of Career Assessment, 25,5874.doi:10.1177/1069072716657826

Shin, S., Rachmatullah, A., Roshayanti, F., Ha, M., \& Lee, J.-K. (2018). Career motivation of secondary students in STEM: A cross-cultural study between Korea and Indonesia. International Journal of Educational Vocational Guidance, 18,203-231. doi:10.1007/s10775-017-9355-0 
Shoffner, M. F., Newsome, D., Barrio Minton, C. A., \& Wachter Morris, C. A. (2015). A qualitative exploration of the STEM career-related outcome expectations of young adolescents. Journal of Career Development, 42, 102-116. doi:10.1177/0894845314544033

Stipanovic, N., \& Woo, H. (2017). Understanding African American students' experiences in STEM education: An ecological systems approach. Career Development Quarterly, 65,192206.doi:10.1002/cdq.12092

Tien, H. S. (1996). The vocational interest structure of Taiwanese high school students. Chinese Report of Guidance and Counseling, 4,69-93.

Tien, H. S. (1999). A qualitative analysis of career barriers perceived by women in Taiwan. Bulletin of Educational Psychology in Taiwan, 31,89-107.

Tien, H. S., \& Wang, Y. (2016). Career counseling research and practice in Taiwan. Career Development Quarterly, 64,231-243. doi:10.1002/cdq.12057

Tien, H. S., Wang, Y. F., \& Liu, L. C. (2009). The role of career barriers in high school students' career choice behavior in Taiwan. Career Development Quarterly, 57,274-288.doi:10.1002/j.21610045.2009.tb00112.x 